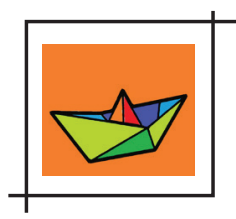

\title{
TEMPESTADE DE GELO E A LIBERDADE MIDIATIZADA
}

\author{
Verônica D'Agostino Piqueira* \\ Lucia Maria Argollo Maciel**
}

Resumo: Este artigo tem como propósito apontar como os ideais de liberdade presentes nos anos de 1960 foram assimilados, estetizados e individualizados nos anos 1970 por meio de um processo de midiatização. Para tal, lança mão do filme Tempestade de Gelo, dirigido por Ang Lee e lançado em 1997, ambientado no Dia de Ação de Graças de 1973.

Palavras-chave: Midiatização. Liberdade. Contracultura. Sociedade do espetáculo. Ang Lee.

0 objetivo deste trabalho é refletir sobre como o conceito de liberdade dos anos de 1960 foi assimilado e individualizado nos anos de 1970, usando como exemplo o filme de drama Tempestade de gelo (Ice storm), de 1997.

Esse filme, de 113 minutos, foi produzido entre 9 de abril e 25 de junho de 1996, baseado no livro homônimo lançado em 1994, escrito por Rick Moody. 0 roteiro foi escrito pelo produtor do filme, James Schamus, e o filme foi dirigido pelo cineasta taiwanês Ang Lee. 0 orçamento foi de US\$ 18 milhões, e a arrecadação nos cinemas, de US\$ 8 milhões.

0 filme conta a história de duas famílias de New Canaan, Connecticut, no dia de ação de graças (Thanksgiving Day) do ano de 1973. A família Hood está à beira da desintegração, pois Benjamin (interpretado por Kevin Kline) não tem se relacionado bem com Elena (Joan Allen), sua esposa, e envolve-se com Janey Carver (Sigourney Weaver), sua vizinha e amiga intima

\footnotetext{
* Mestre em Educação, Arte e História da Cultura pela Universidade Presbiteriana Mackenzie (UPM). Pesquisadora da área de Educação e História Contemporânea, com ênfase em História dos Estados Unidos e História do Cinema e do Audiovisual. Atua como professora no Colégio Magno, no Ensino Fundamental e nos itinerários formativos do novo Ensino Médio, nas disciplinas de Ciências Humanas e Sociais Aplicadas.

** Doutora em Psicologia pela Universidade de São Paulo (USP). Mestre em Psiquiatria pela USP. Participou do Grupo de Ciência Cognitiva (1991 a 2007) do IEE e, posteriormente, do NAP da Escola Politécnica da USP. Atualmente é professora do Instituto Sedes Sapientae. Tem experiência na área de Medicina, com ênfase em Psiquiatria e ensino de Psicopatologia no contexto de trabalho em orientação familiar.
} 
da família. Enquanto isso, Paul (Tobey Maguire), filho de 16 anos do casal, sente-se atraído por uma colega de colégio (Katie Holmes). Já sua irmã Wendy (Christina Ricci), de 14 anos, é bem mais precoce que seus pais imaginam e, na sua necessidade de carinho e afeição, explora sua sexualidade, ora com Mikey (Elijah Wood), ora com seu irmão mais novo Sandy Carver (Adam Hann-Byrd), os filhos do casal Carver. Jim Carver (Jamey Sheridan) é um pai de família ausente, está sempre viajando e sua ausência sequer é notada pelos seus filhos. Os adultos, então, decidem organizar uma festa em que ocorre o jogo das chaves - os homens colocam as chaves do carro em um pote e as mulheres sorteiam uma delas e vão para casa com o dono das chaves.

Apesar de narrado por Paul, não se vê um protagonista único, alternando entre os membros das duas famílias, com destaque para a família Hood. 0 começo do filme estabelece o contexto dos anos de 1970, mostrando roupas e músicas de rock progressivo, e também apresenta as personagens e as situações de cada uma delas separadamente. Após isso, o filme se aproxima mais das personagens e seus dramas.

A trama do filme é relacionada a sexo: as experiências sexuais de Wendy com Mikey e Sandy; Paul tentando fazer sexo com Libbets; a distância entre o casal Elena e Ben; a relação de Ben com Janey; a festa das chaves e a subsequente relação sexual de Elena com Jim Carver.

\section{O CONCEITO DE LIBERDADE}

Para entender o contexto de liberdade presente no filme, é importante, antes, entender a modificação desse conceito desde o lluminismo e o projeto moderno até o período em que a narrativa se passa. Um dos paradigmas mais importantes do projeto moderno é a noção de liberdade, mas, em tempos pré-modernos, a liberdade tinha outro significado, conforme afirma Benjamin Constant em "Da liberdade dos antigos comparada à dos modernos":

Esta última consistia em exercer coletiva, mas diretamente, várias partes da soberania inteira, em deliberar na praça pública sobre a guerra e a paz, em concluir com os estrangeiros tratados de aliança, em votar as leis, em pronunciar julgamentos, em examinar contas, os atos, a gestão dos magistrados; em fazê-los comparecer diante de todo um povo, em acusá-los de delitos, em condená-los ou em absolvê-los; mas, ao mesmo tempo que consistia nisso o que os antigos chamavam de liberdade, eles admitiam, como compatível com ela, a submissão completa do indivíduo à autoridade do todo (CONSTANT, 1985, p. 11).

A liberdade, antes do lluminismo e do projeto moderno, era exercida por meio do exercício coletivo e da política, conceito que não corresponde à noção subjetiva de liberdade individual moderna. Na Modernidade, sob o pilar da racionalização, com a filosofia e a ciência, o 
homem é livre do obscurantismo da religião e capaz de entendimento. 0 homem livre é aquele que conhece a verdade racionalmente concebida e por ela define o seu destino.

Na progressão do tempo, o domínio do capital, o interesse econômico, a razão instrumental e o desprovimento de princípios tomaram conta da cena histórica. A crença de que a razão e a ciência permitiriam ao homem emancipar-se de seu destino e organizar a vida de modo racional e livre acabou por dar lugar a uma ideologia que, ao contrário de seguir o projeto das luzes, desfigurou e reformulou essa ideia, em favor do mercado e do capital. Uma das consequências foi que a racionalidade, em uma forma extrema, então se ligou ao Estado, permitindo o surgimento do nazifacismo e o Holocausto.

Com o fim da Segunda Guerra Mundial, os Estados Unidos estavam em crescente poderio econômico devido aos lucros provenientes de venda de produtos durante a guerra (como armas e munições). Por um lado, durante esses anos de estabilidade e prosperidade, a classe média branca americana estave imersa numa crescente obsessão por consumo, tendo o impulso modernista perdido forças e sido apropriado pela sociedade industrial. No entanto, posteriormente, uma crise na estrutura moral dessa sociedade começou a surgir, um descrédito do sonho americano, que pode ser visto em expressões artísticas como o rock e a literatura beat, que prenunciavam os anos 1960.

0 começo dos anos 1960 foi marcado por um idealismo e entusiasmo nas manifestações socioculturais, mas o choque entre a racionalidade produtiva e os valores morais e sociais do hedonismo consumista cada vez mais conduziram a uma tentativa de afastamento dessa estrutura sociocultural vigente, principalmente depois de 1966. Isso pode ser visto na desconstrução dos princípios e concepções do pensamento ocidental que levaram o mundo à guerra e aos demais prejuízos sociais, e no desenvolvimento de temas antes marginais, como experimentação com drogas e sexo, levando a uma perda da inocência, à revolução sexual e aos protestos juvenis. Para o historiador Theodore Roszak, em seu livro A contracultura, publicado em 1969, são os jovens que se veem na posição única de oposição com a política apática de consenso de seus pais (ROSZAK, 1972, p. 18). Contudo, para ele, os jovens radicais europeus tentavam se aliar aos padrões do passado, associando-se aos trabalhadores contra a burguesia. Pelo contexto histórico, coube aos jovens americanos o papel de questionar a cultura:

Ironicamente, parece que foram os jovens norte-americanos, carentes de melhor background radical, que compreenderam com mais lucidez que, conquanto fatos prementes como a guerra no Vietnã, a injustiça racial e a pobreza enquistada exijam certa dose de ativismo político ao velho estilo, a luta suprema de nossos dias é contra um inimigo muito mais temivel - porque muito menos visivel, - ao qual eu daria o nome de tecnocracia, uma forma social mais desenvolvida nos Estados Unidos do que em qualquer outra sociedade (ROSZAK, 1972, p. 18). 
O autor chama de tecnocracia a forma social de uma sociedade industrial em seu ápice, com ideais de modernização, atualização, racionalização e planejamento, justamente os ideais do projeto moderno que prevaleceram. Para ele, a tecnocracia age de uma forma subliminar, ideologicamente invisivel, levando a sociedade a obedecer às regras da eficiência industrial.

Roszak (1972, p. 34) culpa a geração adulta pela omissão, provavelmente em decorrência do cansaço causado pela guerra e pela busca por segurança e tranquilidade que isso acarretou, mas chama esse torpor de patético, e sugere que foi essa passividade praticamente patológica que fez os jovens assumirem o destaque. Embora ele diga que nos anos de 1950 existiram focos de resistência em nível adulto,

0 fato é que foram os jovens, à sua maneira amadoristica e até mesmo grotesca, que deram efeito prático às teorias rebeldes dos adultos. Arrancaram-nas de livros e revistas escritas por uma geração mais velha de rebeldes, e as transformaram num estilo de vida. Transformaram as hipóteses de adultos descontentes em experiências, embora frequentemente relutando em admitir que às vezes uma experiência redunda em fracasso (ROSZAK, 1972, p. 37).

A busca dos jovens pela liberdade veio com um espírito libertário, focada principalmente nas transformações da consciência, dos valores e do comportamento, na busca de outros espaços e novos canais de expressão para o indivíduo e pequenas realidades do cotidiano. Entretanto, no fim dos anos 1960, esses valores começaram a ser incorporados pelas mídias. Roszak (1972, p. 47) aponta que a imprensa percebeu valores comerciais em exibir a rebelião e que a juventude não soube enfrentar bem a sobrecarga dos meios de comunicação, sociólogos, jornalistas, curiosos e "simpatizantes de fim de semana", acarretando "uma espécie de asfixia da rebeldia através da publicidade contínua, e começa a parecer que para o Sistema esta arma é muito mais eficaz do que a supressão pura e simples", sendo essa a arma exata para derrotar os objetivos da juventude.

Foi dessa maneira que o legado dos anos de 1960 se conformou nas mídias no começo dos anos de 1970. 0 espírito de liberdade, antes vivido socialmente, passou a ser experimentado de modo superficial por meio das mídias. A finalidade ideológica deu lugar a uma finalidade mercadológica da liberdade, percebida pelo consumo.

A liberdade alcançada, aliada ao poderio econômico experimentado nessa época, dava ao sujeito um espaço para decidir seu destino e se reinventar, mas esse espaço gerava uma necessidade de preenchimento para formação da identidade, e a estratégia das mídias foi a de ligar a busca pela identidade ao consumo, provocando uma angústia que veio a ser preenchida com a cultura pop, que sempre está atrelada ao discurso artístico da indústria. 


\title{
TEMPESTADE DE GELO
}

0 filme Tempestade de gelo se passa no ano de 1973, período de transição entre a liberdade experimentada socialmente pelo corpo e a cristalização de uma liberdade experimentada pelas mídias e pelo consumo. A influência da cultura pop pode ser vista no filme mesmo na cena inicial, na narração de Paul Hood, que faz uso de uma metáfora com histórias em quadrinhos para definir a vida familiar:

\begin{abstract}
Na edição 141 do Quarteto Fantástico, publicada em novembro de 1973, Reed Richards tem que usar sua arma de antimatéria em seu próprio filho, que Aannihilus transformou numa bomba atômica humana. Essa era uma situação típica para o Quarteto Fantástico, porque eles não eram como os outros super-heróis. Eles eram mais como uma familia. E quanto mais poder eles tinham, mais eles poderiam causar danos uns aos outros sem saber disso. Esse era o sentido do Quarteto Fantástico: que uma família é como sua antimatéria pessoal. Sua família é o vazio de onde você surge, e o lugar que você retorna quando morre. E esse é o paradoxo - quanto mais perto você é atraído de volta, mais fundo no vazio você vai (TEMPESTADE DE GELO, 1997).
\end{abstract}

Em seu livro Sociedade do espetáculo, publicado originalmente em 1967, o escritor francês Guy Debord (2000) descreve uma mídia e uma sociedade de consumo organizadas em torno da produção e consumo de imagens, mercadorias e eventos culturais. Para ele, o espetáculo é um instrumento para a pacificação e a despolitização, que distrai os sujeitos sociais da plenitude de seus poderes humanos. 0 espetáculo cria um sujeito passivo, alienado e que consome submissamente.

Para Debord (2000), é nos meios de comunicação de massa que o espetáculo se manifesta de forma mais esmagadora, atuando como forma de sustentação da administração da sociedade tecnológica, já que esse controle só pode ser exercido por intermédio dessa força de comunicação instantânea.

\footnotetext{
Na cultura da mídia globalizada, as celebridades são as divindades fabricadas e administradas. São ícones midiáticos, e deuses e deusas da vida cotidiana. Para se tornar uma celebridade, é necessário o reconhecimento como uma estrela no campo do espetáculo, seja com esportes, entretenimento, negócios ou política. As celebridades possuem assessores e agentes de imagem para garantir que continuem a ser vistas e percebidas positivamente pelo público (KELLNER, 2006, p. 126).
}

0 filme se passa em 1973, ano que coincide com o escândalo de Watergate, envolvendo o então presidente dos Estados Unidos, Richard Nixon. No filme, Wendy Hood acompanha a 
trama política pela televisão como quem acompanha o enredo de uma novela. Ela até mesmo sugere que ele deve ser assassinado, como quem torce para o desfecho da trama de um filme. Seu discurso parece ser herdado das mídias, e não demonstra ter o espírito que a geração da década anterior evocava, uma revolta política que pode ser vista por ações sociais. Para Wendy, Nixon é um personagem, tanto que ela se empolga ao achar uma máscara de látex do presidente na casa da família Carver e veste-a antes de sugerir uma experiência sexual com seu amigo Mikey.

Na década de 1970, assimilavam-se os efeitos liberais da revolução social da década anterior de maneira ainda desorientada, aparecendo assim no filme tanto para os pais quanto para os filhos. Apesar de o filme acompanhar uma família, a busca por uma liberdade individual faz que, a despeito da proximidade física, exista um enorme distanciamento emocional entre os personagens. Hobsbawn (1995, p. 316) aponta para uma crise da família que surge da liberação sexual das décadas de 1960 e 1970:

A crise da familia estava relacionada com mudanças bastante dramáticas nos padrões públicos que governam a conduta sexual, a parceria e a procriação. Eram tanto oficiais quanto não oficiais, e a grande mudança em ambas está datada, coincidindo com as décadas de 1960 e 1970. Oficialmente, essa foi uma era de extraordinária de liberalização tanto para os heterossexuais (isto é, sobretudo para as mulheres, que gozavam de muito menos liberdade que os homens) quanto para os homossexuais, além de outras formas de dissidência cultural-sexual.

Embora na década de 1960 a liberação sexual esteja ligada à juventude, a liberdade experimentada nesse momento histórico faz que não seja mais o corpo físico que determina o individuo, assim, a faixa etária socialmente aceita como jovem não é o fator determinante do comportamento. 0 discurso da mídia colabora com essa ideia, mostrando figuras paternas, como as vistas no filme, que se comportam como adolescentes em relação ao sexo. 0 próprio diretor do filme aponta isso, dizendo que "toda a nação está em um período adolescente, experimentando novas coisas, novas regras - até mesmo os adultos se comportam como adolescentes" (FILM SCOUTS, [1997?], tradução nossa). James Schamus, produtor e roteirista, afirmou que escrever o roteiro de Tempestade de gelo foi um exercício de visão dupla. Segundo ele,

Por um lado, eu vi isso bastante do ponto de vista dos filhos. Eu mesmo cresci nos anos 70 [...]. Por outro lado, eu sou um pai, então eu estava realmente olhando para isso do ponto de vista dos pais, que estavam experimentando, pela força e pressão do que estava acontecendo com a sociedade, muitas das mesmas coisas que os filhos (FILM SCOUTS, [1997?], tradução nossa). 
Ang Lee, diretor do filme, diz que "o filme faz paralelos entre o comportamento dos pais e dos filhos. 0 que eles encontram no processo é a natureza humana, e a tempestade de gelo, que te faz ter mais respeito pela natureza. Acontece que nos não somos tão livres assim, afinal" (FILM SCOUTS, [1997?], tradução nossa). E, ao que parece, no filme, toda tentativa dos pais de se comportarem como jovens dá errado.

Aparentemente, a personagem Elena Hood busca uma volta à juventude, e um dos primeiros indícios disso é que ela se afasta do marido. Ao observar a filha Wendy, de 14 anos, andando de bicicleta, relaxada, ela decide em outro momento fazer a mesma coisa. Além disso, Wendy cometia pequenos furtos em uma loja e, ao tentar imitar esse comportamento, Elena é pega. Frustrada, volta para casa e chora.

Ben, marido de Elena, sentindo-se afastado da esposa, busca um relacionamento extraconjugal com sua vizinha, Janey. Embora seus encontros sejam sexualmente satisfatórios, Ben sente falta de intimidade, o que acaba afastando Janey.

Quando ocorre a festa da troca de casais, Ben tem esperanças de que Janey trapaceie e pegue a chave de seu carro e, ao conversar com ela, percebe o distanciamento e a falta de interesse, e bebe a ponto de passar mal. Janey pega a chave de outro homem e sai, fazendo que Ben saia do sorteio das chaves, indo para o banheiro, onde vomita. Elena, inicialmente contra a troca de casais, já percebia sinais da relação de Ben e Janey e, como forma de mostrar sua insatisfação, decide participar do jogo e acaba por fazer par com o marido de Janey. Jim inicialmente reluta sobre fazer sexo com Elena, oferecendo a ela uma carona para casa, mas Elena insiste para que eles façam sexo no carro, mais uma vez imitando um comportamento adolescente. 0 sexo acontece de forma desajeitada e Jim tem problemas, frustrando outra tentativa de Elena de comportar-se como jovem, a deixando-a desolada.

Enquanto os pais estão perdidos experimentando uma sexualidade juvenil, os filhos, jovens de verdade, estão perdidos numa imitação que parodia a vida sexual dos pais. No começo do filme, Wendy se encontra com Mikey e pergunta se ele havia contado para seu irmão Sandy sobre eles. Ele nega e, então, quase de forma ensaiada, eles se beijam, como um treino que, pelo contexto da cena, parece recorrente. Mais tarde, na casa dos Carver, Wendy precisa usar o banheiro e encontra o irmão mais novo de Mikey, Sandy. Eles conversam na porta do banheiro e Wendy o provoca: "Eu mostro a minha se você mostrar o seu". Os dois entram no banheiro, e Wendy abaixa sua calça, mas Sandy se desespera e grita, atraindo a atenção de Janey. Ao confrontar os dois no banheiro, Janey afasta Wendy e diz-Ihe que "o corpo de alguém é o seu templo, sua primeira e última posse. Seus pais devem ter te ensinado que na adolescência o nosso corpo tende a nos trair", mas é essa mesma Janey que está experimentando um comportamento adolescente, ao procurar sexo com o pai de Wendy e depois na festa da troca de casais.

Em um momento um pouco mais adiante do filme, Ben vai à casa dos Carver ter um encontro sexual com Janey, que, incomodada com a necessidade de intimidade de Ben, 0 
abandona e sai de casa sem avisar. Ben se veste e, ao procurar por Janey, vai até a sala da casa, onde se depara com sua filha Wendy vestindo a máscara de Nixon enquanto toca as partes intimas de Mikey, o filho mais de velho do casal Carver. Nesse momento, Ben se exalta com Mikey e leva a filha para casa, tentando aconselhá-la a preservar sua sexualidade.

De fato, no filme, todas as vezes que os pais tentam demonstrar uma atitude paterna, essa intenção parece simulada e vazia de sentido. Nesse contexto, ter um filho não faz que o pai se configure no papel social de pai. Esse papel precisa ser construido, e, nos personagens do filme, essa construção parece vazia. Bauman (2001) afirma que, nessa nova configuração da modernidade, a identidade não mais nasce com o sujeito, assumindo uma construção artificial. Nas palavras do autor:

Os seres humanos não mais "nascem" em suas identidades. Como disse Jean-Paul Sartre em frase célebre: não basta ter nascido burguês - é preciso viver a vida como burguês. [...] Precisar tornar-se o que já se é é a caracteristica da vida moderna - e só da vida moderna (não da "individualização moderna", a expressão sendo evidentemente pleonástica; falar da individualização e da modernidade é falar de uma e da mesma condição social). A modernidade substitui a determinação heterônoma da posição social pela autodeterminação compulsiva e obrigatória. Isso vale para a "individualização" por toda a era moderna - para todos os períodos e todos os setores da sociedade (BAUMAN, 2001, p. 40, grifo do autor).

Enquanto os pais estão na festa, Mikey liga para Wendy e convida-a para ir ver a tempestade nas ruas, e Wendy diz que talvez o acompanhe. Mikey vai sozinho até a piscina onde ele e Wendy se beijam, e logo Wendy vai para a casa dos Carver, mas encontra Sandy, com quem conversa e brinca com um boneco. Ela tira a roupa do boneco e pergunta se pode ficar na cama com ele. Eles vão para o quarto, acham uma garrafa de vodca e decidem beber. Depois, cobrem-se, despem-se e Sandy fala que ama Wendy. Ambos adormecem com um aspecto de felicidade e carinho.

Já Paul, o filho mais velho do casal Hood, que gosta de Libbets Casey, divide um apartamento na universidade com Francis Davenport, que caçoa da virgindade de Paul e relaciona-se com todas as garotas de quem o amigo demonstra gostar. Paul marca de se encontrar com Libbets e, ao chegar em casa, vê que Francis estava lá, já com alguma intimidade com a garota. Paul acha remédios no banheiro da casa e decide oferecer ao amigo, pois sabia que misturando com cerveja ele logo dormiria. Contudo, Libbets vê a cena e decide tomar também. Francis desmaia e ela fica entorpecida. Nesse momento, Paul decide dizer que tem sentimentos por ela, que responde dizendo que ele é como um irmão, e Paul afirma que não é a primeira vez que ele ouve isso de uma garota. Libbets dorme, Paul fica um tempo a encarando e decide ir embora. 
A experiência de Wendy e Sandy com álcool e a de Paul, Francis e Libbetz com álcool e drogas é diferente da experimentação psicodélica dos jovens da década de 1960. Para Roszak (1972, p. 161), "a experiência psicodélica é um elemento importante da rejeição radical da sociedade adulta por parte dos jovens". Mais uma vez, o comportamento dos adolescentes e dos adultos é similar, já que na festa da troca de casais em que os pais estão todos bebem e fumam. Encontramos no filme uma perversão das ideias de expansão da consciência por meio de drogas, discurso comum nos anos de 1960, e um consumo de escapismo, sem sentido e sem esperança.

Quando Mikey sai para ver a tempestade, ele está deprimido pela pressão de seus amigos e de sua família, e arrisca a própria vida ao pular do trampolim em direção à piscina vazia, embora nada aconteça nessa brincadeira. Mikey continua brincando de maneira perigosa, mas, cansado, decide encostar em um anteparo de metal da estrada e fica hipnotizado observando um poste tombado pela tempestade. Então, um fio se solta e encosta no anteparo, eletrocutando-o até a morte.

Quando Ben está voltando para casa, depara com o corpo de Mikey e leva-o até a casa dos Carver. Ao chegar lá, grita por Jim e Janey, mas encontra primeiro sua esposa e sua filha. Depois, Jim chega e carrega o corpo do filho para dentro de casa, e a familia Hood se junta, sem se encarar.

Os Hood vão juntos até a estação de trem buscar Paul, que aparenta estar feliz agora que se afastou do ocorrido e por encontrar sua familia reunida. No carro, ele percebe a tristeza de seus parentes e a família fica em silêncio. Ben começa a chorar desesperançoso, terminando assim o filme.

De acordo com o diretor, Ang Lee, os personagens precisaram deparar com a tempestade de gelo para terem mais respeito pela natureza humana. "Acontece que nós não somos tão livres assim, afinal" (FILM SCOUTS, [1997?], tradução nossa). Essa ideia do diretor parece ir de acordo com as ideias de Bauman (2001, p. 24, grifo do autor):

\footnotetext{
Sentir-se livre das limitações, livre para agir conforme os desejos, significa atingir o equilibrio entre os desejos, a imaginação e a capacidade de agir: nossos desejos e que nem uma nem os outros ultrapassam nossa capacidade de agir. 0 equilibrio pode, portanto, ser alcançado e mantido de duas maneiras diferentes: ou reduzindo os desejos e/ou a imaginação, ou ampliando nossa capacidade de ação. Uma vez alcançado o equilibrio, e enquanto ele se mantiver, "libertação" é um slogan sem sentido, pois falta-Ihe força motivacional.
}

Para esse autor, o tipo de liberdade experimentada pelos personagens do filme é vazia, pois vem da busca de um equilíbrio por meio da resignação aos desejos e a liberdade só faz sentido se surgir da ação. 


\section{CONCLUSÃO}

Tempestade de gelo é um filme de 1997 baseado num livro de 1994, tendo um tempo de maturação para, por meio de uma trama de época, analisar os efeitos da experiência de liberdade vivida na década de 1970, posicionando-se sobre as consequências sentidas pelas pessoas que viveram esse período.

A diferença entre ser adolescente e ser adulto pode ser definida socialmente em termos de idade, mas, na experiência prática, a diferença está nas experiências acumuladas. Essas experiências não necessariamente levam a um amadurecimento real, e a necessidade constante de redefinição da identidade, tão característica da modernidade, pode levar a atitudes débeis, com justificativas vazias. Isso pode ser entendido no contexto do filme de Ang Lee, que parece defender que uma pessoa pode envelhecer, mas suas confusões e incertezas permanecem.

No filme, a busca da liberdade individual leva ao afastamento das familias e ao egoísmo, trocando uma experiência social compartilhada por uma busca de realização nunca alcançada.

Os filhos adolescentes carecem de maturidade e, ao buscarem algum tipo de conexão com outras pessoas, acabam se frustrando - muito disso em decorrência de não poderem contar com pais presentes, já que esses estão absortos em sua busca por liberdade individual.

Essa tentativa de liberdade praticada nos anos de 1960 pode ser entendida como uma resistência a um contexto de racionalidade que põe em xeque a individualidade do sujeito. Já nos anos de 1970, período em que o filme se passa, essa experiência acaba sendo incorporada no discurso midiático, midiatizando e diluindo uma experiência que já havia sido autêntica. A necessidade humana da construção de uma identidade, em um período em que ficava cada vez mais difícil naturalizar os modos de ser, acabou sendo incorporada em produtos e práticas midiatizadas. A imagem que cada um tem de si começa a vir por meio da representação incorporada em objetos de consumo e modos de agir. Dessa forma, a experiência individual e espontânea foi desaparecendo, dando espaço a uma experiência estética produzida pela indústria, mas que, como aponta o filme, teve consequências na vida e no comportamento das pessoas. 


\section{Ice Storm and freedom through media}

Abstract:This paper aims to point out how the ideals of freedom present in the 1960's were assimilated, aestheticized and individualized in the 1970's through a process of mediatization. To this end, we analyze the film Ice Storm, directed by Ang Lee and released in 1997, set on Thanksgiving Day in 1973.

Keywords: Mediatization. Freedom. Counterculture. Society of the spectacle. Ang Lee.

\section{REFERÊNCIAS}

BAUMAN, Z. Modernidade líquida. Rio de Janeiro: Zahar, 2001.

CONSTANT, B. Da liberdade dos antigos comparada à dos modernos. In: MORAES, J. 0. de. (ed.). Filosofia politica. Porto Alegre: LEtPM, 1985. p. 9-25. v. 2.

DEBORD, G. A sociedade do espetáculo: comentários sobre a sociedade do espetáculo. Rio de Janeiro: Contraponto, 2000.

FILM SCOUTS. The /ce Storm: about the story. [1997?]. Disponivel em: http://www.filmscouts. com/scripts/matinee.cfm?Film=ice-sto\&tFile=synopsis. Acesso em: 10 jan. 2019.

HOBSBAWN, E. Era dos extremos: o breve século XX: 1914-1991. São Paulo: Companhia das Letras, 1995.

KELLNER, D. Cultura da mídia e triunfo do espetáculo. In: MORAES, D. de (org.). Sociedade midiatizada. Rio de Janeiro: Mauad, 2006. p. 119-147.

ROSZAK, T. A contracultura: reflexões sobre a sociedade tecnocrática e a oposição juvenil. 2. ed. Petrópolis: Vozes, 1972.

TEMPESTADE de gelo. Direção: Ang Lee. Century City, CA: Fox Searchlight Pictures, 1997. DVD (113 min). 